\title{
Can rehabilitation exercise alter the oxidative profile in stroke patients?
}

\author{
Braga AS ${ }^{1}$, Franco SC ${ }^{1}$, Figueiredo VB ${ }^{1}$, Veras MMS'2, Vilela DA ${ }^{3}$, Kairy $D^{2}$ and Tatmatsu-Rocha JC ${ }^{1 *}$ \\ ${ }^{1}$ Medicine School, Physiotherapy Department, Federal University of Ceara, Fortaleza, Ceara, Brazil \\ ${ }^{2}$ Centre for Interdisciplinary Research, École de Réadaptation, Université de Montréal, Canada \\ ${ }^{3}$ Medicine School, Physiotherapy Department, Federal University of Goias, Jatai, Goias, Brazil
}

\begin{abstract}
Oxidative stress can trigger the deterioration of the cerebral extracellular endothelial matrix and may lead to a stroke event. There is evidence that rehabilitation exercise alters the oxidative profile. This systematic review intends to observe in the literature if rehabilitation exercise can contribute to modifying the oxidative profile in the stroke. For it, we investigated works from 2012 until August 2017, in the PubMed, Lilacs and PEDro databases. Initially, 30 documents were selected, but only one article met the inclusion criteria. These results showed that new studies must be carried out to affirm that the therapeutic exercises could improve the oxidative profile in stroke patients.
\end{abstract}

\section{Introduction}

Stroke is the most common type since $85 \%$ to $90 \%$ of people were diagnosed with ischemic stroke [1]. Pathophysiology of stroke, there is a change in the encephalic circulation, leading to limitations in the performance of body structure and function [2]. Ischemic stroke remains to be one of the most severe neurological diseases, which results in permanent deterioration in motor and cognitive abilities [3]. Plastic reorganization occurs immediately after stroke. Following focal damage to the motor cortex and its descending pathways, the surviving portions of the brain usually undergo substantial structural and functional reorganization [4]. Because of the difficulties in measuring the stress biomarkers in stroke rehabilitation research is crucial to better understand the pathophysiology.

However, because of the difficulties in measuring unstable free radicals in human samples, the degree of oxidative stress can be determined by measuring the stable end-products of oxidatively modified proteins, lipids, and DNA [5].Some studies have shown alterations in the levels of oxidative stress in stroke patients, such as that of Ning et al [6], in which it was suggested that oxidative stress could trigger the deterioration and active remodelling of the extracellular endothelial matrix. Other authors also indicate that oxidative stress would play a critical role in the cerebrovascular dysfunction induced by angiotensin-converting enzyme type 2 (ACE2) deficiency by converting angiotensin II to angiotensin and thus protecting against the effects of angiotensin, which could explain some differences among users regarding post-stroke symptoms. These events could occurs due to high production of reactive oxygen species and reactive nitrogen species associated with the lack of antioxidants [7]. This imbalance generates lipid peroxidation, protein denaturation, DNA breakdown, and causes cellular damage, which can lead to autophagy, necrosis, or cellular apoptosis [8].

Because of these repercussions, the number of studies seeking to identify means to control the effects of oxidative stress is increasing.
According to Austin et al. (2014), researchers with animals in ischemic conditions suggest that a high load of exercises is capable of stimulating genes and proteins that protect the brain from damage from oxidative stress without increasing the number of free radicals, besides regulating reactive substances that act as markers of this phenomenon. Moreover, physical activity influence the cellular oxidative profile, and therefore, interventions with exercise could promote an antioxidative effect and thus prevent the worsening of the condition $[9,10]$. Functional plasticity is a mechanism in which the neural networks that remain after an ischemic brain injury undergo structural and synaptic changes to restore loss of function [11]. In this context, it is suggested that the rehabilitation of the AVE occurs as early as possible, due to the phenomenon of neuronal plasticity, through which recovery of part of the lost movements occurs. Early intervention could return motor capacity as well as allow the user to carry out their daily life activities alone [12].

The present study aims to identify if there is evidence that the therapeutic exercises are capable of acting on the effects of oxidative stress from the stroke.

\section{Methods}

A rapid systematic review of the literature was conducted in search of original articles on therapeutic exercises on the effects of oxidative stress in the Stroke on the PubMed, Lilacs and PEDro databases. The search period was January 2012 until August 2017. The search syntaxes for the database Pubmed are (Oxidative Stresses) OR Stresses, Oxidative) OR Stress, Oxidative) AND (Strokes) OR Cerebrovascular

Correspondence to: Tatmatsu-Rocha JC, Medicine School, Physiotherapy Department, Federal University of Ceara, Fortaleza, Ceara, Brazil, Tel: $+55(85)$ 3366- 8632; Email: tatmatsu@gmail.com

Received: October 20, 2017; Accepted: November 30, 2017; Published: December 04, 2017 
Accident) OR Cerebrovascular Accidents) OR CVA (Cerebrovascular Accident) OR CVAs (Cerebrovascular Accident) OR Cerebrovascular Apoplexy) OR Apoplexy, Cerebrovascular) OR Vascular Accident, Brain) OR Brain Vascular Accident) OR Brain Vascular Accidents) OR Vascular Accidents, Brain) OR Cerebrovascular Stroke) OR Cerebrovascular Strokes) OR Stroke, Cerebrovascular) OR Strokes, Cerebrovascular) OR Apoplexy) OR Cerebral Stroke) OR Cerebral Strokes) OR Cerebral Strokes) OR Stroke, Cerebral) OR Strokes, Cerebral) OR Stroke, Acute) OR Acute Stroke) OR Acute Strokes) OR Strokes, Acute) OR Cerebrovascular Accident, Acute) OR Acute Cerebrovascular Accident) OR Acute Cerebrovascular Accidents) OR Cerebrovascular Accidents, Acute) AND (Therapy, Exercise) OR Exercise Therapies) OR Therapies, Exercise) OR Rehabilitation Exercise) OR Exercise, Rehabilitation) OR Exercises, Rehabilitation) OR Rehabilitation Exercises) OR Remedial Exercise) OR Exercise, Remedial) OR Exercises, Remedial) OR Remedial Exercises) OR (Modalities, Physical Therapy) OR Modality, Physical Therapy) OR Physical Therapy Modality) OR Physical Therapy Techniques) OR Physical Therapy Technique) OR Techniques, Physical Therapy) OR Physiotherapy (Techniques) OR Physiotherapies (Techniques)) OR Neurological Physiotherapy) OR Physiotherapy, Neurological) OR Neurophysiotherapy). The search syntaxes for the database Lilacs and PEDro was oxidative stress AND stroke. We searched for articles in the English and Portuguese languages, published in the last five years. This study was evaluated by two independent reviewers and was included in a second entry database, Excel, and then reviewed by both. Any disagreements were resolved by discussion between reviewers to reach consensus or by a third reviewer.
Original articles were included whose central theme related to therapeutic exercise in post-stroke, and the primary outcome was an evaluation of biomarkers of oxidative stress. Studies where the primary focus was not oxidative stress or studies in animals.

\section{Results and discussion}

A total of 30 articles identified in the databases of which one included in the synthesis, a process detailed in Figure 1.

In this work, 30 studies with the keywords defined were initially listed. However, 25 studies were excluded because the majority did not present oxidative stress analysis in their methodology or did not present studies related to rehabilitation exercise [13-37]. Five articles [1,38-41] were included in their summaries the keywords. However, during the reading of the full text, only the paper of Ciancarelli et al [40] met the inclusion criteria of our research.

About Ciancarelli work, patients selected to participate in this study were enrolled at the Nova Salus Rehabilitation Center from October 2011 to January 2012. The participants inclusion criteria was: Participants within the first thirty days after the first moderate or severe ischemic stroke event; presenting hemiparesis who could control the trunk in the seated posture for at least ten seconds, be able to walk and not being sedentary.

During the study, the National Institutes of Health Stroke Scale (NIHSS), the modified Rankin Scale (mRS), the Barthel Index and the Katz Index were used as measuring tools. The protocol used in the research had as primary objective to recover neurological deficits and

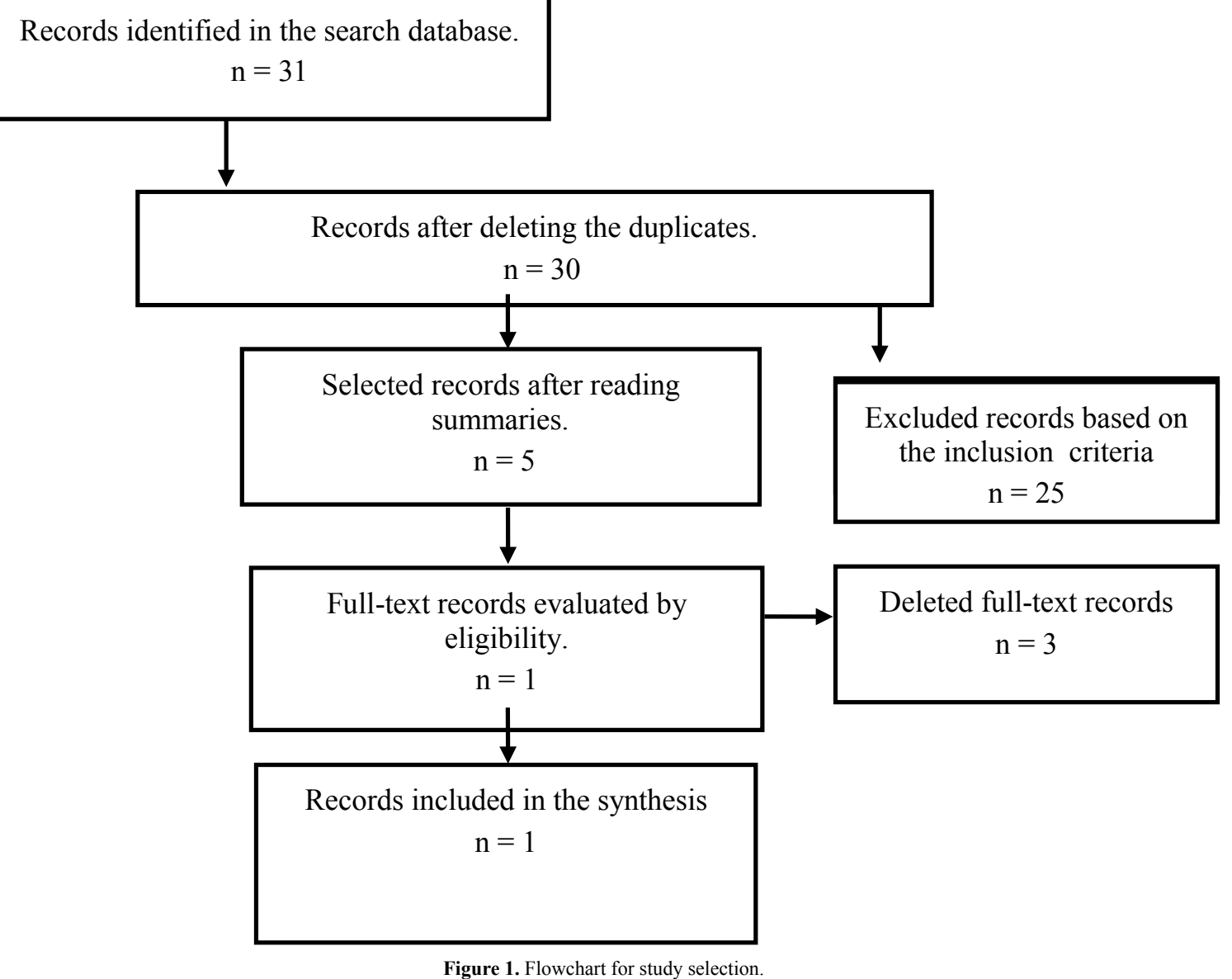


to recover functional abilities during the activities of daily life and to improve the self-care. The proposed treatment was performed for six weeks, for six days, with two sessions of 45 minutes per day.

Blood analysis of stroke patients was performed before and aftercare. No significant differences were found in blood pressure, MBI and HDL-C values between the two groups before and after rehabilitation. The amounts of cholesterol, triglycerides and LDL-C were higher in stroke patients than in the control group, values that did not change significantly at the end of treatment. Significant results of our review it is that the antioxidant capacity of plasma was lower in those who had the stroke before and after therapeutic intervention. Besides, values of peroxidative by-products and Nitric Oxide metabolites have been shown to be high in stroke patients compared to healthy subjects. These costs decreased significantly in stroke patients although they remained at higher levels than the control group and reinforced that rehabilitation exercise could alter the oxidative profile. Limitation: Possible limitations of this review are the date of publication and a limited number of databases included in the search.

\section{Conclusion}

Systematic reviews have the objective of bringing state of the art on a whole subject of scientific relevance. This report has provided an updated and considerably expanded picture of the role of rehabilitation exercises in the oxidative profile of people who had the stroke and providing an opportunity for advancing research in this area. In this study, it is concluded that although there is evidence that exercise rehabilitation changes the oxidative profile, there are few studies to ensure that exercise rehabilitation improves oxidative stress in stroke patients. Therefore, caution would be encouraged in interpreting these findings because of the small number of research included in this review.

\section{References}

1. Sosa PM, Schimidt HL, Altermann C, Vieira AS, Cibin FWS, et al. (2015) Physical exercise prevents motor disorders and striatal oxidative imbalance after cerebral ischemia-reperfusion. Braz J Med Biol Res 48: 798-804. [Crossref]

2. Faria CDCdM, Silva SM, Corrêa JCF, Laurentino GEC, Teixeira-Salmela LF (2012) Identification of ICF participation categories in quality-of-life instruments utilized in cerebrovascular accident victims. Rev Panam Salud Publica 31: 338-44. [Crossref]

3. Knecht S, Hesse S, Oster P (2011) Rehabilitation after stroke. Deutsches Ärzteblatt International 108: 600

4. Li S (2017) Spasticity, Motor Recovery, and Neural Plasticity after Stroke. Front Neurol 8: 120. [Crossref]

5. Hsieh Y-W, Lin K-C, Korivi M, Lee T-H, Wu C-Y, et al. (2014) The reliability and predictive ability of a biomarker of oxidative DNA damage on functional outcomes after stroke rehabilitation. Int J Mol Sci 15: 6504-6516. [Crossref]

6. Ning M, Sarracino DA, Kho AT, Guo S, Lee S-R, et al. (2010) Proteomic temporal profile of human brain endothelium after oxidative stress. Stroke 42: 37-43. [Crossref]

7. Tsai N-W, Chang Y-T, Huang C-R, Lin Y-J, Lin W-C, et al. (2014) Association between oxidative stress and outcome in different subtypes of acute ischemic stroke. Biomed Res Int 2014: 256879. [Crossref]

8. Shirley R, Ord EN, Work LM (2014) Oxidative Stress and the Use of Antioxidants in Stroke. Antioxidants (Basel) 3: 472-501. [Crossref]

9. Radak Z, Zhao Z, Koltai E, Ohno H, Atalay M (2013) Oxygen consumption and usage during physical exercise: the balance between oxidative stress and ROS-dependent adaptive signaling. Antioxid Redox Signal 18:1208-1246. [Crossref]

10. García-Mesa Y, Colie S, Corpas R, Cristòfol R, Comellas F, et al. (2015) Oxidative stress is a central target for physical exercise neuroprotection against pathological brain aging. J Gerontol A Biol Sci Med Sci 71: 40-49. [Crossref]

11. Caleo M (2015) Rehabilitation and plasticity following stroke: insights from roden models. Neuroscience 311: 180-194.
12. da Costa FA, da Silva DLA, da Rocha VM (2011) Severidade clínica e funcionalidade de pacientes hemiplégicos pós-AVC agudo atendidos nos serviços públicos de fisioterapia de Natal (RN). Revista Ciência \& Saúde Coletiva 16.

13. Hirai DM, Jones JH, Zelt JT, da Silva ML, Bentley RF, et al. (2017) Oral N-acetylcysteine and exercise tolerance in mild chronic obstructive pulmonary disease. J Appl Physiol (1985) 122: 1351-1361. [Crossref]

14. Brooks SD, DeVallance E, d'Audiffret AC, Frisbee SJ, Tabone LE, et al. (2015) Metabolic syndrome impairs reactivity and wall mechanics of cerebral resistance arteries in obese Zucker rats. Am J Physiol Heart Circ Physiol 309: H1846-H59. [Crossref]

15. Ahn B, Beharry AW, Frye GS, Judge AR, Ferreira LF (2015) NAD (P) H oxidase subunit $\mathrm{p} 47$ phox is elevated, and 47 phox knockout prevents diaphragm contractile dysfunction in heart failure. Am J Physiol Lung Cell Mol Physiol 309: L497-L505. [Crossref]

16. Münzel T, Gori T, Keaney Jr JF, Maack C, Daiber A (2015) Pathophysiological role of oxidative stress in systolic and diastolic heart failure and its therapeutic implications. Eur Heart J 36: 2555-2564. [Crossref]

17. Ramos JS, Dalleck LC, Tjonna AE, Beetham KS, Coombes JS (2015) The impact of high-intensity interval training versus moderate-intensity continuous training on vascular function: a systematic review and meta-analysis. Sports Med 45: 679-692. [Crossref]

18. Maharlooei MK, Bagheri M, Solhjou Z, Jahromi BM, Akrami M, et al (2011) Adipose tissue derived mesenchymal stem cell (AD-MSC) promotes skin wound healing in diabetic rats. Diabetes Res Clin Pract 93: 228-234. [Crossref]

19. Ranjbar K, Nazem F, Nazari A (2016) Effect of exercise training and L-arginine on oxidative stress and left ventricular function in the post-ischemic failing rat heart. Cardiovascular toxicology 16: 122-129.

20. Bender SB, DeMarco VG, Padilla J, Jenkins NT, Habibi J, et al. (2015) Mineralocorticoid receptor antagonism treats obesity-associated cardiac diastolic dysfunction. Hypertension 2015: 65: 1082-1088. [Crossref]

21. McCarty MF, editor NADPH Oxidase Activity in Cerebral Arterioles Is a Key Mediator of Cerebral Small Vessel Disease-Implications for Prevention2015: Multidisciplinary Digital Publishing Institute.

22. Sun S, Chen X, Gao Y, Liu Z, Zhai Q, et al. (2016) Mn-SOD upregulation by electroacupuncture attenuates ischemic oxidative damage via CB1R-mediated STAT3 phosphorylation. Mol Neurobiol 53: 331-343. [Crossref]

23. Kones R, Rumana U (2014) Cardiovascular prevention: components, levels, early origins, and metrics. Hosp Pract (1995) 42: 84-95. [Crossref]

24. Becher PM, Lindner D, Fluschnik N, Blankenberg S, Westermann D (2013) Diagnosing heart failure with preserved ejection fraction. Expert opinion on medical diagnostics 7 : 463-474.

25. Jung YS, Lee S-W, Park JH, Seo HB, Choi BT, et al. (2016) Electroacupuncture preconditioning reduces ROS generation with NOX4 down-regulation and ameliorates blood-brain barrier disruption after ischemic stroke. J Biomed Sci 23: 32. [Crossref]

26. Houston MC (2013) The role of nutrition, nutraceuticals, vitamins, antioxidants, and minerals in the prevention and treatment of hypertension. Altern Ther Health Med 19: 32. [Crossref]

27. Burcu GB, Osman C, Asli C, Namik OM, Nese BT (2016) The protective cardiac effects of?-myrcene after global cerebral ischemia/reperfusion in C57BL/J6 mouse Acta Cir Bras 31: 456-462. [Crossref]

28. Azevedo PS, Polegato BF, Minicucci MF, Paiva SAR, Zornoff LAM (2016) Cardiac remodeling: concepts, clinical impact, pathophysiological mechanisms and pharmacologic treatment. Arq Bras Cardiol 106: 62-69. [Crossref]

29. Fiorelli SKA, Vianna LM, Oliveira CABd, Fiorelli RKA, Barros BCS, et al. (2014) The effects of supraphysiological supplementation of b-carotene in spontaneously hypertensive rats (SHR and SHR-sp). Revista do Colégio Brasileiro de Cirurgiões 41: 351-355.

30. Imosemi IO, Imosemi I (2013) The role of antioxidants in cerebellar development. A review of literature. Int J Morphol 31: 203-210.

31. Yassin LS, Fukui C, Pereira PCD, Olandoski M, Aveles PR, et al. (2012) Effect of a commercial enteral diet with added antioxidants on total plasma thiol, protein carbonyl and malondialdehyde levels after a stroke. Revista de Nutrição 25: 247-257.

32. Ardisson LP (2010) Influência da taurina na remodelação ventricular após o infarto do miocárdio. 
33. Castro IM, Silva E (2012) Alimentos funcionais: um enfoque gerontológico. Rev Bras Clin Med 10: 24-28.

34. Lustosa BHB (2013) Influência do extrato de chá verde na remodelação cardíaca após o infarto agudo do miocárdio.

35. Rubio MC, González PM, Ramos C, Lewin PG, Friedman SM, et al. (2013) Oxidative stress assessed in saliva from patients whit acute myocardial infarction. A preliminary study. Acta Odontol Latinoam 26: 116-120. [Crossref]

36. Gonçalves AdF (2013) Influência da suplementação de vitamina D na remodelação ventricular após o infarto do miocárdio.

37. Fatureto-Borges F, Drager LF (2013) Apneia obstrutiva do sono e o endotélio disfucionante. Rev Soc Cardiol Estado de Säo Paulo 23: 71-76.
38. Schimidt HL, Vieira A, Altermann C, Martins A, Sosa P, et al. (2014) Memory deficits and oxidative stress in cerebral ischemia-reperfusion: Neuroprotective role of physical exercise and green tea supplementation. Neurobiol Learn Mem 114: 242-250. [Crossref]

39. Austin MW, Ploughman M, Glynn L, Corbett D (2014) Aerobic exercise effects on neuroprotection and brain repair following stroke: a systematic review and perspective. Neurosci Res 87: 8-15. [Crossref]

40. Ciancarelli I, De Amicis D, Di Massimo C, Carolei A, Giuliana Tozzi Ciancarell M (2012) Oxidative stress in post-acute ischemic stroke patients after intensive neurorehabilitation. Curr Neurovasc Res 9: 266-273. [Crossref]

41. Tataradze E, Chabashvili N, Sanikidze T (2005) Physical rehabilitation of stroke patients and redox alterations. Georgian Med News 2005: 66-69. [Crossref]

Copyright: $@ 2017$ Braga AS. This is an open-access article distributed under the terms of the Creative Commons Attribution License, which permits unrestricted use, distribution, and reproduction in any medium, provided the original author and source are credited. 